\title{
Histological and immunohistochemical investigation on ovarian development and plasma estradiol levels in the swordfish (Xiphias gladius $L_{\text {.) }}$
}

\author{
A. Corriero, F. Acone, ${ }^{1}$ S. Desantis, D. Zubani, M. Deflorio, G. Ventriglia, C.R. Bridges, ${ }^{2}$ \\ M. Labate, ${ }^{3}$ G. Palmieri, ${ }^{1}$ B. G. McAllister, ${ }^{4}$ D. E. Kime, ${ }^{4}$ G. De Metrio \\ Department of Animal Health and Well-being, University of Bari, Valenzano (BA), Italy; ${ }^{1}$ Department of \\ Animal Biology, University of Sassari, Italy; ${ }^{2}$ Institut für Zoophysiologie, Lehrstuhl für \\ Stoffwechselphysiologie, Heinrich Heine Universität, Düsseldorf, Germany; ${ }^{3}$ Department of Zoology, \\ University of Bari, Italy; ${ }^{4}$ Department of Animal and Plant Sciences, The University of Sheffield, UK
}

(C)2004, European Journal of Histochemistry

The paper reports a histological and immunohistochemical description of oocyte growth and ultrastructural aspects of zona radiata (ZR) formation as well as the relationship between plasma estradiol-17 $\beta$, $\left(\mathrm{E}_{2}\right)$ levels and ovarian development in swordfish (Xiphias gladius L.) from the Mediterranean Sea. Ovaries were inactive during March to mid April; maturation occurred during late April to June and spawning in June and July.

Zona radiata formation starts, as Pas positive material, in oocytes at the lipid stage. In this stage a deposit of electrondense material between oolemma and follicular cells appears. In the cortical alveoli stage and through the early vitellogenic stage, the deposition of a moderately electrondense material occurred on the inner side of the ZR. Finally, in late vitellogenic oocytes a third layer, made of microfibrillar material, appeared. The immunohistochemical analyses revealed that the initial internalisation of hepatic zona radiata proteins (Zrp) in the swordfish oocyte starts before the uptake of vitellogenin ( $\mathrm{Vtg}$ ) and that it is associated with the low previtellogenic $E_{2}$ plasma levels, while a significant $E_{2}$ increase in plasma is associated with the beginning of $\mathrm{Vtg}$ uptake. This would appear to confirm the hypothesis that the differential and sequential induction of zonagenesis and vitellogenesis may reflect a general feature of teleost oogenesis.

Correspondence: Gregorio De Metrio Department of Animal Health and Well-being - University of Bari, S.P. per Casamassima km. 3, I-70010 Valenzano (BA), Italy.

Phone: international +39080 5443907 .

Fax: international +39080 5443908 .

E-mail: g.demetrio@veterinaria.uniba.it

Key words: Swordfish; Xiphias gladius; Ovary; Reproduction; Immunohistochemistry; Estradiol

Paper accepted on October 11, 2004.

European Journal of Histochemistry

2004; vol. 48 issue 4 (Oct-Dec):413-422

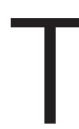
he swordfish (Xiphias gladius L.) is a gonochoristic, cosmopolitan pelagic top predator and represents an important commercial fishing resource. Reports on the reproduction of this species mainly consider swordfish from the northwestern Atlantic (Taylor \& Murphy, 1992; Arocha \& Lee, 1995; Arocha, 2002) and Pacific (DeMartini et al., 2000). Information regarding reproduction of swordfish from the Mediterranean Sea are limited to studies based on distribution of eggs and larvae (Potoschi et al., 1994), on seasonal variations of the gonadosomatic index $\left(\mathrm{I}_{\mathrm{G}}\right)$ (de la Serna et al., 1996), and on preliminary histological observations (de la Serna et al., 1996; Desantis et al., 1998).

Oocyte growth in female teleosts is mainly due to the incorporation of exogenous proteins such as vitellogenin ( $\mathrm{Vtg}$ ) and zona radiata proteins ( $\mathrm{Zrp}$ ) under the control of sexual hormones. These proteins are synthesized by the liver under the stimulation of estradiol, transported in the bloodstream to the follicular layer and then endocytated by oocytes and used for the formation of both yolk and vitelline envelop (Wallace, 1985; Celius and Walter, 1998).

Data on the relationship between oocyte development and estradiol levels have been reported for several captive (Matsuyama et al., 1991; Kjesbu et al., 1996; Lee et al., 2002) and wild (Susca et al., 2001) teleosts, but not for swordfish.

The aim of this study is to describe, by means of histological, immunohistochemical and ultrastructural methods, the developmental stages of swordfish oocytes and to provide data on i) seasonal ovarian development and reproductive period of the species in the North Ionian Sea and ii) the relationship among the changes in $17 \beta$,-estradiol $\left(E_{2}\right)$ plasma levels, relative ovarian mass (gonadosomatic index, $\mathrm{I}_{G}$ ) and oocyte growth. 


\section{Materials and Methods}

\section{Sample collection}

Ovaries were obtained from 116 swordfish with lower jaw-fork length $\left(L_{L J F}\right)>140 \mathrm{~cm}$. All fish sampled were adult according to de la Serna et al. (1996). Fish were captured during March ( $n=9)$, April $(n=10)$, May $(n=20)$, June $(n=13)$, July $(n=25)$, August $(n=14)$, September $(n=8)$, October $(n=7)$, November $(n=6)$ and December $(n=4)$ 2000-2001 in the North Ionian Sea (Gulf of Taranto) by commercial vessels using long lines or drift nets. Soon after capture, $L_{\sqcup F}$ was measured to the nearest $\mathrm{cm}$; the ovaries were removed and the gonad weight $\left(W_{G}\right)$ measured to the nearest $\mathrm{g}$. At landing, the eviscerated body weight $\left(W_{B}\right)$ was measured to the nearest $100 \mathrm{~g}$. The gonadosomatic index $\left(\mathrm{I}_{\mathrm{G}}\right)$ was calculated as $100 *\left(\mathrm{~W}_{\mathrm{G}} / \mathrm{W}_{\mathrm{B}}\right)$. Gonad slices ( $1 \mathrm{~cm}$ thick) of all the specimens sampled were fixed in Bouin's solution for $12 \mathrm{~h}$ for light microscopical studies. Small ovarian pieces from three vitellogenic females were fixed in 3\% glutaraldehyde in $0.1 \mathrm{M}$ sodium cacodilate buffer $(\mathrm{pH} 7.4)$ for $3 \mathrm{~h}$ at $0-4^{\circ} \mathrm{C}$ for ultrastructural investigations.

For $E_{2}$ measurements, blood from 51 specimens was collected from the heart with heparinized syringes and cannula. Syringes and cannula were rinsed in advance with a solution containing 200 $\mathrm{mM} \mathrm{NaCl} ; 8.6 \mathrm{KCl}, 8000 \mathrm{IU} \mathrm{ml}^{-1}$ sodium heparin and $1 \mathrm{mM}$ phenylmethylsulphonylfluoride (PMSF, Sigma), pH 7.3. Blood was kept on ice after sampling at sea and then centrifuged at $5000 \mathrm{~g}$ for 15 min. Plasma was collected using a plastic pipette and stored at $-20^{\circ} \mathrm{C}$ in the laboratory (usually $<4 \mathrm{~h}$ after capture).

\section{Histology and conventional histochemistry}

The fixed samples were dehydrated in increasing ethanol concentrations, clarified in Histolemon and embedded in paraffin wax. Sections ( $5 \mu \mathrm{m}$ thick) were processed for haematoxylin - eosin, Mallory's trichrome, Periodic acid-Schiff (Pas) reaction and immunohistochemistry. The oocyte classification used an adaptation of the schemes commonly used for teleosts (Matsuyama et al., 1988; Mandich et al., 2002; Corriero et al.; 2003). 0ocyte size was determined on histological slides using a Quantimet 500W (Leica, Cambridge, U.K.) image analyser, by measuring the maximum and minimum oocytediameters of at least 30 oocytes from each developmental stage.

\section{Transmission electron microscopy}

After washing in sodium cacodilate buffer, the samples were post-fixed with $1 \% \mathrm{OsO}_{4}$, dehydrated through increasing ethanol concentrations, and embedded in Araldite. Thin sections $(60-80 \mathrm{~nm}$ thick) were cut, counterstained with uranyl acetate and lead citrate and observed with a Zeiss EM 109.

\section{Immunohistochemistry}

For the immunolocalization of Zrp and Vtg, ovarian sections were deparaffinized, hydrated and pretreated for 30 min with $0.3 \% \mathrm{H}_{2} \mathrm{O}_{2}$ in methanol to inhibit endogenous peroxidase activity. They were then incubated for 30 min in normal horse serum (NHS) diluted 1:10 in phosphate buffered saline (PBS) (0.01 M phosphate buffer pH 7.4 containing $0.15 \mathrm{M} \mathrm{NaCl}$ ) to block non-specific binding sites for immunoglobulins. The sections were then incubated for $1 \mathrm{~h}$ at $37^{\circ} \mathrm{C}$ in a moist chamber with the antiserum diluted in PBS containing $0.1 \%$ BSA. The working dilutions were: anti-salmon Zrp 0-173 (abSalm-Zrp; Biosense, Bergen, Norway), 1: 100; anti-swordfish Vtg (abSwo-Vtg; Eicker, 2001), 1: 10000. The immunohistochemical visualisation was obtained using the Vectastain Universal Elite Kit (Desantis et al., 2000).

To confirm the specificity of the immunostaining, the following control staining procedures were carried out: (1) replacement of primary antibody with normal horse serum; (2) omission of the primary antibody; (3) replacement of primary antibody with pre-immune rabbit serum; (4) replacement of primary antibody with rabbit anti-mouse albumin serum.

\section{$E_{2}$ measurement}

$200 \mu$ l of plasma were extracted three times with $5 \mathrm{ml}$ dichloromethane, the extracts redissolved and estradiol measured by ELISA using acetylcholinesterase as tracer and an antisera raised against estradiol-6-CM0-BSA in sheep provided by Prof Zvi Yaron (Tel Aviv). Inter and intraassay variations for the method were less than 10\%. Full details of the methodology are given in Cuisset et al. (1994) and Nash et al. (2000).

\section{Statistical analysis}

$E_{2}$ plasma levels and $I_{G}$ were expressed as mean \pm S.E. The analysis of variance was carried out by the GLM procedure (SAS, 1988), and comparison between least square means was performed with 


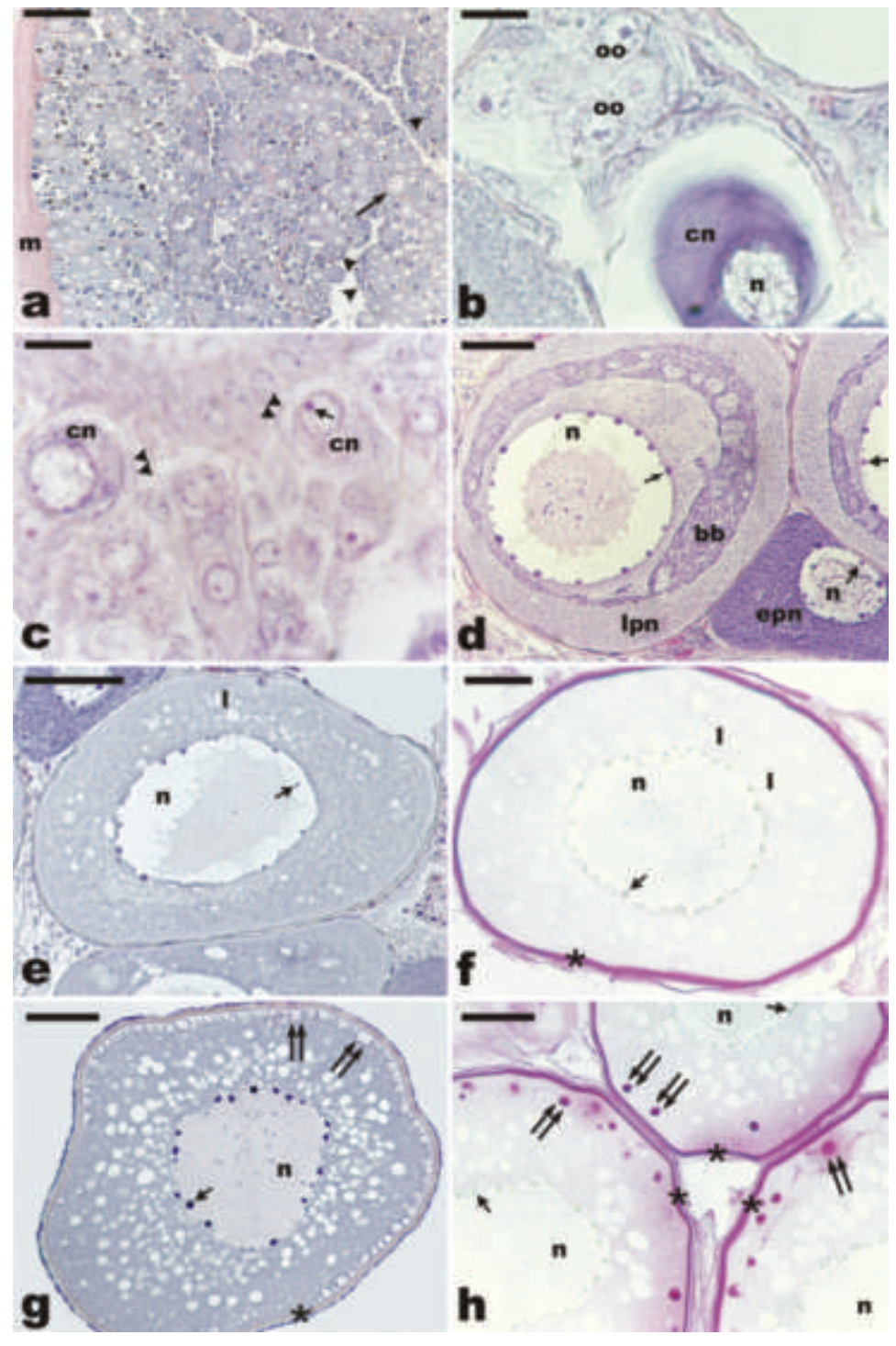

Figure 1. Micrographs of swordfish ovaries at different maturational stages. (a) ovary showing the muscle wall and ovigerous lamellae. Haematoxylineosin staining (bar $=500 \mu \mathrm{m}$ ). (b) A cluster of oogonia adjacent to an advanced chromatin nucleolus stage oocyte. Haematoxylin-eosin staining (bar $=10 \mu \mathrm{m})$. (c) Oocyte at early chromatin nucleolus stage in association with a single follicular cell. Haematoxylin-eosin staining (bar $=15 \mu \mathrm{m}$ ). (d) Oocytes at early and late perinucleolar stage. Haematoxylin-eosin staining (bar $=30 \mu \mathrm{m})$. (e) Oocyte at lipid stage showing weak ooplasm basophily and lipid droplets. Haematoxylin-eosin staining (bar $=50 \mu \mathrm{m})$. (f) Thin Pas+ ZR in an oocyte at lipid stage $($ bar $=30 \mu \mathrm{m})$. (g) Oocyte at cortical alveoli stage. Haematoxylin-eosin staining (bar $=\mathbf{5 0} \mu \mathrm{m}$ ). (h) Oocytes at cortical alveoli stage showing the appearance of Pas+ cortical alveoli $($ bar $=50 \mu \mathrm{m})$. Arrowhead, perinucleolar-stage oocyte; arrow, lipid-stage oocyte; double arrowhead, follicular cell; small arrow, nucleolus; double arrow, cortical alveolf; asterisk, zona radiata; bb, Balbiani's body; cn, chromatin nucleolus-stage oocyte; epn, early perinucleolar-stage oocyte; Ipn, late perinucleolar-stage oocyte; I, lipid droplets; m, muscle wall; n, nucleus; oo, oogonium.
Tukey-Kramer adjustment. Statistical significance was accepted at $p<0.05$.

\section{Results}

\section{Histological analysis}

Swordfish ovaries were paired organs elongated along the cranio-caudal axis, located in the abdominal cavity and suspended by a mesovarium. Anteriorly the right and left ovaries were free, while their posterior ends joined in a common oviduct, which opened to the exterior in the urogenital pore. In cross-section the ovary showed a round profile. The right and left ovaries often differed in length and weight.

The ovaries were surrounded by a thick muscle wall and the parenchyma showed numerous ovigerous lamellae containing oogonia and oocytes, the latter in different stages of growth (Figure 1 a). Diameters of oogonia and oocytes at different developmental stages are reported in Table I.

Oogonia, generally found in clusters of a few cells interspersed in the interstitial tissue, were round or oval unstained cells with a euchromatic nucleus

Table I. Diameter of oogonia and oocytes at different developmental stages in the swordfish (mean in $\mu \mathrm{m} \pm$ S.E.).

\begin{tabular}{llll}
\hline \hline & $n$ & Diameter & $95 \%$ C.I. \\
\hline Oogonia & 30 & $10.17 \pm 0.46$ & \pm 0.9744 \\
Chromatin nucleolus stage & 33 & $16.77 \pm 0.88$ & \pm 1.7889 \\
Perinucleolar stage & 39 & $74.88 \pm 4.10$ & \pm 8.3041 \\
Lipid stage & 31 & $169.70 \pm 5.35$ & \pm 11.3498 \\
Cortical alveoli stage & 32 & $231.20 \pm 3.30$ & \pm 7.1842 \\
Early vitellogenesis stage & 33 & $351.03 \pm 7.58$ & \pm 15.4326 \\
Late vitellogenesis stage & 31 & $567.70 \pm 27.66$ & \pm 57.8894 \\
Post vitellogenesis stage & 34 & $848.60 \pm 13.43$ & \pm 27.5649
\end{tabular}




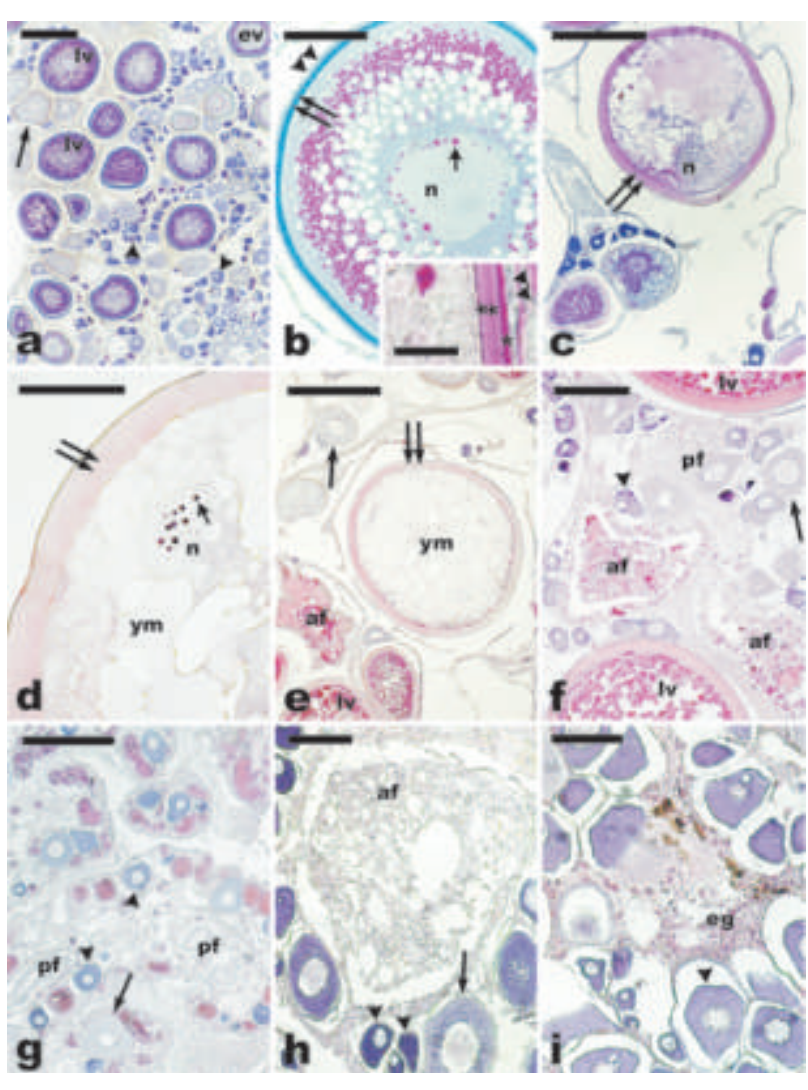

Figure 2. Micrographs of swordfish ovaries at different maturational stages (a) Oocytes at perinucleolar, lipid, early and midlate vitellogenesis stages. Mallory's trichrome staining (bar = $500 \mu \mathrm{m})$. (b) Oocyte at mid-late vitellogenesis stage. Mallory's trichrome staining (bar $=\mathbf{1 0 0} \mu \mathrm{m}$ ). Inset: detail of a late vitellogenesis stage oocyte showing a double-layered ZR. Pas reaction (bar = $15 \mu \mathrm{m})$. (c) Migratory nucleus oocyte, showing coalescence of yolk and lipids, together with vitellogenic and perinucleolar oocytes. Haematoxylin-eosin staining (bar $=\mathbf{5 0 0} \mu \mathrm{m}$ ). (d) Detail of a postvitellogenic oocyte with dissolving nuclear envelope. Haematoxylin-eosin staining (bar $=\mathbf{1 0 0} \mu \mathrm{m}$ ). (e) Spawning ovary where a hydrated oocyte together with vitellogenic, previtellogenic and atretic oocytes are visible. Haematoxylin-eosin staining (bar $=\mathbf{5 0 0} \mu \mathrm{m}$ ). (f) Partially running ovary showing a postovulatory follicle, previtellogenic oocytes, two early atretic oocytes and part of two healthy vitellogenic oocytes. Haematoxylin-eosin staining (bar $=200 \mu \mathrm{m})$. (g) Numerous postovulatory follicles in an ovary devoid of vitellogenic oocytes. Haematoxylin-eosin staining (bar $=300 \mu \mathrm{m})$. (h) Regressing ovary showing a late atretic follicle and previtellogenic oocytes (bar = $100 \mu \mathrm{m}$ ). (i) Regressing ovary showing previtellogenic oocytes, irregular cell masses containing pigmented inclusions and eosinophilic granulocytes. Haematoxylin-eosin staining (bar $=100 \mu \mathrm{m})$. Arrowhead, perinucleolar-stage oocyte; arrow, lipidstage oocyte; double arrowhead, follicular cells; double arrow, zona radiata; small arrow, nucleolus; asterisk, zona radiata externa; double asterisk, zona radiata interna; af, atretic follicle; eg, eosinophilic granulocytes; n, nucleus; pf, postovulatory follicles; ym, yolk mass.

showing a large, eccentric nucleolus (Figure lb). Oogonia were present in all samples analysed although they could be more easily observed in inactive or regressing ovaries.
Chromatin nucleolus stage oocytes had a large eccentric nucleus showing chromatin strands. The nucleus of the smallest oocytes at this stage showed a single eccentric nucleolus, while a few peripheral nucleoli were observed in the largest ones. During this stage, ooplasm basophily increased progressively with oocyte growth. At this stage, follicular cells, squamous in shape were associated with the oocytes (Figures 1b, c).

Perinucleolar stage oocytes had numerous nucleoli adjoining the nuclear envelope. The early perinucleolar oocytes showed intense ooplasm basophily, while the late ones displayed decreased ooplasm basophily and the presence of the basophilic, perinuclear, Balbiani's body. Flat follicular cells constituted a single complete layer around the oocytes (Figure 1d).

Lipid stage oocytes exhibited a further reduction of ooplasm basophily and were characterised by the presence of small lipid droplets and the appearance of a thin Pas+ ZR interposed between oolemma and follicular cells (Figures le, f).

Cortical alveoli stage oocytes were characterized by an increase in number of lipid droplets as well as the presence of both Pas+ and Pas- cortical alveoli whose number increased with oocyte size. Zona radiata thickness reached up to $2 \mu \mathrm{m}$ (Figures $1 \mathrm{~g}, \mathrm{~h}$ ).

Early vitellogenesis stage oocytes were characterised by small spherical eosinophilic granules (yolk globules) in the peripheral ooplasm. In this stage ZR thickness reached $5 \mu \mathrm{m}$ and the follicular cell layer became cubic (Figure $2 a$ ).

Late vitellogenesis stage oocytes showed further accumulation of yolk granules that progressively filled the entire ooplasm (Figures. 2a, b). Zona radiata thickness showed a remarkable increase up to $40 \mu \mathrm{m}$ and, in Pas stained sections, appeared to be constituted by two layers: an external layer (zona radiata externa, $\mathrm{ZRE}$ ) and an internal one (zona radiata interna, $\mathrm{ZRI}$ ). Zona radiata externa was thinner and more intensely stained with Pas than ZRI (Figure 2b).

Ovaries with vitellogenic oocytes were observed in specimens captured during late April to late July.

Post-vitellogenesis stage oocytes were characterized by: i) migration of the nucleus towards the animal pole associated with contemporaneous progressive coalescence of lipid droplets and yolk globules (Figure 2c); ii) germinal vesicle breakdown (Figure 2d); iii) ooplasm hydration and complete detachment of the follicular cells (Figure 2e). 


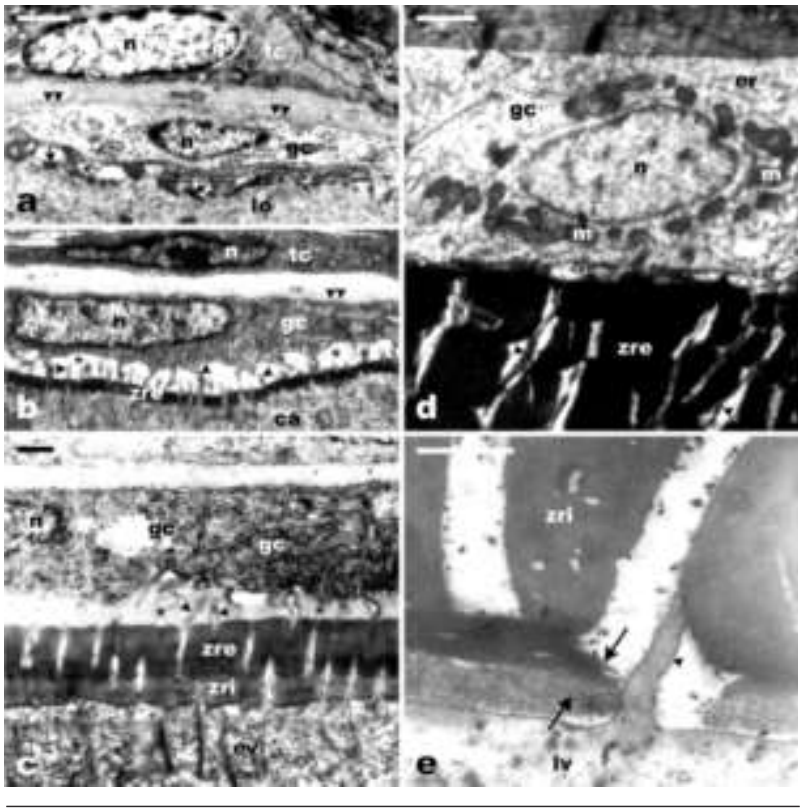

Figure 3. Electron micrographs showing morphological changes during the development of the zona radiata. (a) Lipid stage oocyte separated from a squamous granulosa cell by a subfollicular space. Deposits of electrondense material are found on the oolemma (bar $=10 \mu \mathrm{m}$ ). (b) During the early cortical alveoli stage short microvilli emerging from both the oocyte and squamous granulosa cell show contacts. Oocyte microvilli penetrate poro canals placed in the electrondense zona radiata externa (bar = $1 \mu \mathrm{m})$. (c) Oocyte at early vitellogenesis stage surrounded by a zona radiata constituted by a zona radiata externa and a zona radiata interna. Oocyte microvilli emerge in the electron-lucent subfollicular space and contact granulosa cells (bar $=1 \mu \mathrm{m}$ ). (d) Granulosa cell and zona radiata externa surrounding an oocyte at late vitellogenesis stage. Note that the granulosa cell is cubic in shape and its cytoplasm contains a number of mitochondria and an extensive endoplasmic reticulum. The pore canals contain oocyte microvilli (bar = $1 \mu \mathrm{m})$. (e) The zona radiata interna of a late vitellogenesis oocyte show two additional moderately electrondense bands (bar $=0.5 \mu \mathrm{m}$ ). ca, cortical alveoli stage oocyte; er, endoplasmic reticulum; ev, early vitellogenic oocyte; gc, granulosa cell; lo, lipid stage oocyte; Iv, late vitellogenic oocyte; $m$, mitochondria; $n$, nucleus; tc, thecal cell; zre, zona radiata externa; zri, zona radiata interna; arrow, moderately electrondense bands in the zona radiata interna; asterisk, subfollicular space; arrowhead, microvillus; double arrowhead: basement membrane; small arrow, deposit of electrondense material.

Ovaries with post-vitellogenesis stage oocytes were observed in specimens captured during early June to late July.

Convoluted post-ovulatory follicles, characterized by hypertrophic granulosa cells delimiting an irregular lumen, were clearly observed in the ovaries of only 4 of 38 specimens captured during June to late July. In two specimens, post-ovulatory follicles coexisted with late vitellogenic oocytes (Figure 2f), while the ovaries of the other two fish had only chromatin nucleolus and perinucleolar stage oocytes (Figure $2 \mathrm{~g}$ ).

Atretic follicles were present in the ovaries of all

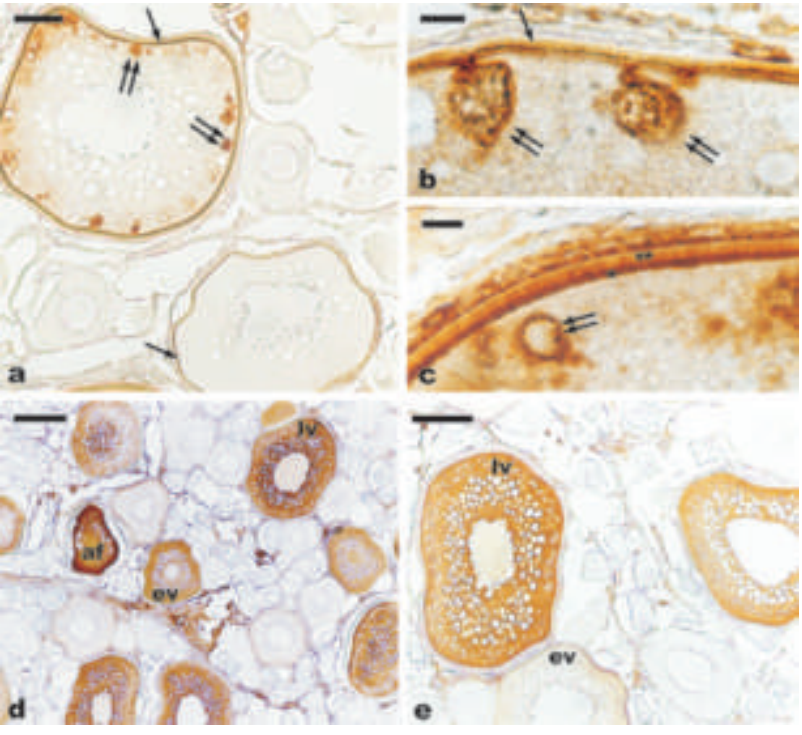

Figure 4. Micrographs of swordfish ovaries at different maturational stages. (a) Immunostaining with abSal-Zrp. Immunoreactivity is localized in the $Z R$ and cortical alveoli (bar $=\mathbf{5 0}$ $\mu \mathrm{m})$. (b) Detail of an oocyte showing abSal-Zrp immunopositive ZR and cortical alveoli: note the connection between these two structures (bar $=10 \mu \mathrm{m})$. (c) Detail of a vitellogenic oocyte immunostained with abSal-Zrp. The antiserum reacted more strongly in the ZRI than ZRE. Positive material can be observed also in the cortical ooplasm and in the follicular layer (bar $=10$ $\mu \mathrm{m})$. (d) Immunohistochemical staining with abSwo-Vtg. (bar = $100 \mu \mathrm{m})$. (e) abSwo-Vtg showed a weak reaction with the ooplasm of oocytes histologically classified in early vitellogenesis stage and a strong reaction with late vitellogenic oocytes (bar = $\mathbf{1 0 0}$ um). Arrow, zona radiata; double arrow, cortical alveoli; asterisk, zona radiata interna; double asterisk, zona radiata externa; af, atretic follicles; ev, early vitellogenic oocyte; Iv, late vitellogenic oocyte;

fish caught during late April to late July. In early atretic follicles (Figures 2e, $f$ ) the nucleus and the ZR lost their structural integrity and the yolk underwent degeneration and was phagocytized by hypertrophied granulosa cells. In late atretic follicles (Figure $2 \mathrm{~h}$ ) the yolk was no more visible and the entire oocyte was invaded by granulosa cells.

Regressing ovaries, collected from specimens captured between June and November, were characterized by chromatin nucleolus and perinucleolar stage oocytes, vitellogenic atretic oocytes, and irregular cell masses containing pigmented inclusions (melanomacrophagic centres). Cells containing eosinophilic granules were sometimes observed in the connective tissue and around degenerating oocytes (Figures $2 \mathrm{~h}, \mathrm{i}$ ).

\section{Electron microscopy}

Ultrastructural observations were carried out to study the appearance as well as the development of 


\begin{tabular}{llllll} 
& $n$ & $I_{G}$ & $95 \%$ C.I. & $E_{2}\left(n g \mathrm{~mL}^{-1}\right)$ & $95 \%$ C.I. \\
\hline Perinucleolar/lipid stage & 10 & $0.35 \pm 0.01 \mathrm{a}$ & \pm 0.0245 & $1.02 \pm 0.12 \mathrm{a}$ & \pm 0.2727 \\
Cortical alveoli stage & 9 & $0.50 \pm 0.04 \mathrm{a}$ & \pm 0.0826 & $1.88 \pm 0.41 \mathrm{ab}$ & \pm 0.9491 \\
Early/late vitellogenesis stage & 14 & $1.88 \pm 0.29 \mathrm{a}$ & \pm 0.6152 & $7.91 \pm 1.06 \mathrm{bc}$ & \pm 2.2944 \\
Post-vitellogenesis stage & 9 & $9.11 \pm 0.92 \mathrm{~b}$ & \pm 2.1236 & $11.17 \pm 3.59 \mathrm{c}$ & \pm 8.2831 \\
Regressing & 9 & $1.42 \pm 0.37 \mathrm{a}$ & \pm 0.8596 & $5.05 \pm 0.57 \mathrm{ac}$ & \pm 1.3103
\end{tabular}

Table II. Changes in gonadosomatic index $\left(\mathrm{I}_{\mathrm{G}}\right)$ and $17 \beta$-estradiol $\left(E_{2}\right)$ plasma levels during swordfish ovarian development. $I_{G}$ and $E_{2}$ values are mean \pm S.E. of samples grouped according to the maximum oocyte stage observed in the ovaries or evidence of recent reproductive activity (regressing). Means with different superscripts within the same column are significantly different $(p<0.05)$.

the ZR during the oocyte growth.

The follicle (granulosa) cells formed a complete unilayer around the oocyte and were supplied with an external basal lamina. Oocytes at lipid stage (Figure 3a) showed a squamous granulosa cell layer (c. $1 \mu \mathrm{m}$ thick) containing a flattened euchromatic nucleus, and their electron-lucent cytoplasm displayed rough endoplasmic reticulum (RER), small Golgi complex and vesicles. Granulosa cells and oocytes were separated by an electron-lucent subfollicular space (c. $200 \mathrm{~nm}$ thick) and spots of electrondense substance were evident on oolemma (Figure 3a).

In oocytes at early cortical alveoli stage (Figure 3b), short microvillar projections emerged from granulosa cells, passed through the subfollicular space (about $800 \mathrm{~nm}$ thick), and contacted microvilli projecting from the oocyte. Oocyte microvilli penetrated the pore canals $(150 \mathrm{~nm}$ wide) of a discontinuous layer of electrondense homogeneous material (500 nm thick) covering the oolemma. This structure represents the developing ZRE (Figure 3b). A thin layer of homogeneous moderately electrondense material started to be deposited in the inner layer of the ZR.

In early vitellogenesis stage oocytes (Figure $3 c$ ), the granulosa cells were cubic in shape with an increase in cytoplasm organella. The ZR reached a thickness of about $5 \mu \mathrm{m}$ and appeared to be constituted of two layers. The inner layer (ZRI) was up to $1 \mu \mathrm{m}$ thick and was less electrondense than ZRE and showed a reticular appearance. Both ZRI and ZRE were traversed by pore canals containing oocyte microvilli which emerged in the subfollicular space and contacted granulosa cells (Figure $3 \mathrm{c}$ ).

In late vitellogenesis stage (Figure $3 d$ ) the cubic granulosa cells measured c. $5 \mu \mathrm{m}$ in height and showed increased RER and mitochondria. The ZR reached a thickness of $40 \mu \mathrm{m}$ and appeared entirely electrondense so that it was very difficult to distinguish the thinner ZRE from the thicker and slightly less electrondense ZRI. In this stage a third ZR layer (300 nm thick), constituted by a microfilamentous substance and perpendicularly oriented between ZRI and oolemma, occurred (Figure 3e). This layer appeared to be arranged in two bands different in electrondensity, the inner one being more electrondense than the outer one.

\section{Immunohistochemistry}

abSal-Zrp reacted with oocytes having a minimum diameter of $180 \mu \mathrm{m}$. Initially, the antiserum reacted only in the area corresponding to the $Z R$ (Figure 4a). In larger oocytes (diameter 200-250 $\mu \mathrm{m})$, some positive cortical alveoli appeared to be connected to the positive ZR (Figures $4 a, b$ ). In more developed oocytes (diameter $>250 \mu \mathrm{m}$ ) the antiserum reacted more strongly in the ZRI than ZRE. In these oocytes the presence of immunopositive peripheral vesicles as well as cortical ooplasm material was evident. Positive material was also seen in the follicular cell layer (Figure 4c).

abSwo-Vtg reacted with ooplasm of oocytes having a minimum diameter of $250 \mu \mathrm{m}$ (Figures $4 d$, e). A weak staining intensity was observed in the ooplasm of oocytes histologically classified in early vitellogenesis stage, while the ooplasm of late vitellogenic oocytes displayed a strong staining intensity (Figure 4e). The immunostaining with abSwo$\mathrm{Vtg}$ and abSbr-Vtg was also found in the connective tissue and sometimes the follicular cell layer and the ZR. No immunostaining was observed in control sections or in ovaries devoid of vitellogenic oocytes.

\section{Changes in $I_{G}$ and $E_{2}$ plasma levels during ovarian development}

Changes in $I_{G}$ and $E_{2}$ plasma levels during ovarian development are reported in Table II.

Mean $I_{G}$ values rose from $0.35 \pm 0.01$ in inactive specimens that exhibited perinucleolar or lipid stage as their maximum oocyte stage, to $0.50 \pm$ 0.04 in fish with oocytes at cortical alveoli stage and to $1.88 \pm 0.29$ in animals with vitellogenic oocytes. Mean $\mathrm{I}_{\mathrm{G}}$ values increased significantly ( $p<$ 0.05 ) to $9.11 \pm 0.92$ in individuals with oocytes at post-vitellogenesis stage. In post-spawning and regressing specimens, mean $\mathrm{I}_{\mathrm{G}}$ values decreased significantly $(p<0.05)$ to $1.42 \pm 0.37$. 
$E_{2}$ plasma levels followed similar changes to the one observed in $\mathrm{I}_{G}$, showing a slight increase in fish with cortical alveoli stage oocytes $(1.88 \pm 0.41 \mathrm{ng}$ $\mathrm{ml}^{-1}$ ) compared to specimens with only perinucleolar and lipid stage oocytes ( $\left.1.02 \pm 0.12 \mathrm{ng} \mathrm{mL}^{-1}\right)$. Plasma E2 rose in vitellogenic female swordfish to $7.91 \pm 1.06 \mathrm{ng} \mathrm{mL}^{-1}$ ( $p=0.055$, close to the threshold level of statistical significance) and reached the maximum value close-to spawning ( $11.17 \pm 3.59$ $\mathrm{ng} \mathrm{mL}^{-1}$ ). After spawning, $\mathrm{E}_{2}$ plasma levels fell to $5.05 \pm 0.57 \mathrm{ng} \mathrm{mL}^{-1}$.

\section{Discussion}

This study reports a histological and immunohistochemical description of oocyte growth in the swordfish as well as of some ultrastructural aspects of ZR formation and provides data on the temporal pattern of ovarian maturation of the species in the North Ionian Sea and on the relationship between ovarian development, $I_{G}$ and $E_{2}$ plasma levels.

In the previous studies on swordfish ovaries (de la Serna et al., 1996; Arocha, 2002), only four developmental stages were described, as, far for providing a detailed study of oogenesis, the aim of the histological descriptions was confined to define the fecundity pattern.

The morphological features of the swordfish oocyte developmental stages here reported are in agreement with those described in other teleost species (Matsuyama et al., 1988; Corriero et al., 2003). The main structural changes associated with oocyte development include: i) increase of cytoplasm organelles, evidenced by increased ooplasm basophily and appearance of Balbiani's body, the latter considered as a centre for the biogenesis of cell organelles (Coello \& Grim, 1990); ii) lipid synthesis and accumulation; iii) appearance of cortical alveoli; iv) yolk accumulation; v) migration of the nucleus to the animal pole and simultaneous coalescence of lipids and yolk; vi) ooplasm hydration.

The simultaneous presence of all of the oocyte developmental stages in spawning specimens indicates that swordfish has an asynchronous oocyte development and it is a multiple spawner, as already reported by Arocha (2002) for the northwestern Atlantic swordfish. This spawning pattern is also confirmed by the simultaneous presence of advanced vitellogenesis stage oocytes and post-ovulatory follicles in some ovaries.

During December to mid-April no vitellogenic oocytes were observed in the ovaries from swordfish caught in the North Ionian Sea. Although the number of samples analysed was limited, this finding indicates that, in the area under investigation, swordfish ovaries are inactive during late autumn-early spring. Maturation occurred during late April to June when ovaries contained vitellogenic oocytes. The spawning period, shown by the presence of post-vitellogenesis stage oocytes and post-ovulatory follicles, occurred in June and July. In fact, post-vitellogenesis stage oocytes, destined to be imminently spawned, and post-ovulatory follicles, which become soon indistinguishable from ovarian connective tissue, are evidence of imminent and recent spawning, respectively (Hunter et al., 1986).

Arocha \& Lee (1995) reported in the subtropical northwestern Atlantic the presence of active mature female swordfish (females with yolked oocytes) during all months except July, while spawning females (females with hydrated oocytes) were found mainly from December to February but also in March, May and June. Spawning female swordfish were caught during March-July in the central North Pacific (DeMartini et al., 2000). Thus, the temporal pattern of swordfish ovarian cycle appears to differ among geographical areas. In the Mediterranean, the presence of a spawning peak in July has been reported on the basis of larval findings (Potoschi et al., 1994) and seasonal changes of $I_{G /}$ (de la Serna et al., 1996). Megalofonou et al. (1995) in a study based on age estimation of juveniles by means of the count of presumed otoliths daily growth increments, reported a spawning period during late June to late August with a peak in July. In the present study, no evidence of recent or imminent spawning has been found in any of the 14 specimens captured during August.

Oocyte growth in fish, as in other oviparous vertebrates, is mainly due to the incorporation of exogenous proteins (Wallace, 1985). Vtg is a precursor of egg yolk proteins synthesized by the liver of female oviparous vertebrates during sexual maturation (Wallace, 1985). In teleosts, ZR formation is a complex phenomenon that involves proteins of hepatic origin (Oppen-Berntsen et al., 1992a, 1992b). Zona radiata, also termed chorion, eggshell, and vitellin envelope, is involved in prevention of polyspermy during fertilization and protection against mechanical damage to the developing embryo (Walther, 1993). Both Vtg and hepatic Zrp are transported through the blood to the ovaries 
where they are incorporated by growing oocytes. Synthesis of Zrp and Vtg is interrelated in teleosts because both processes are controlled by estradiol 17- $\beta$ (Wallace, 1985; Oppen-Berntsen et al., 1992a, 1992b; Celius \& Walter, 1998).

An immunohistochemical study (Hyllner et al., 1994) revealed that in rainbow trout the formation of the vitelline envelope precedes the active uptake of $\mathrm{Vtg}$ during oocyte development.

Immunochemical analysis of plasma Vtg and Zrp levels in Atlantic salmon (Celius \& Walter, 1998) revealed a preferential induction of Zrp after estradiol injection and suggested an ordered sequence of initiation of zonagenesis and vitellogenesis during teleost sexual maturation.

Our electron microscopy observations revealed that ZR formation starts in oocytes at the lipid stage as a deposit of electrondense material between oolemma and follicular cells. In the cortical alveoli stage and through the early vitellogenic stage, the deposition of a moderately electrondense material occurred on the inner side of the ZR. Finally, in late vitellogenic oocytes a third layer, made of microfibrillar material, appeared. Ovary histological sections stained with Pas reaction revealed a thin $Z R$ in oocytes at the lipid stage (oocyte diameter c. $150 \mu \mathrm{m}$ ). Oocytes at this developmental stage did not show immunoreactivity with abSal-Zrp. This could indicate that the first step of ZR formation is represented by glycoproteins synthesised within the follicle. More developed oocytes (diameter about $180 \mu \mathrm{m}$ ) started to incorporate exogenous Zrp, as revealed by the appearance of abSal-Zrp immunopositivity. abSalZrp immunopositive material was localised initially only in the vitelline envelope and subsequently also in the cortical ooplasm, where it was contained in some cortical alveoli. The discrepancy observed in the ZR reactivity to Pas and abSal-Zrp during follicle growth may depend on the lacking of exogenous Zrp in oocytes with diameter $<180 \mu \mathrm{m}$ as well as on the low sensitivity of the eterologous antibody used. The immunohistochemical findings, at least, can be considered reliable because Zrp is structurally conserved among teleostean fish (Oppen-Berntsen et al., 1999). In addition, as reported in the product specification sheet, the antibody used cross-reacts well with Zrp from different teleosts, including Perciformes species.

Cortical alveoli, also termed yolk vesicles, are generally considered to be endogenous oocyte products, frequently seen in association with Golgi apparatus, which are released into the perivitellin space at fertilization to prevent polyspermy (Selman et al., 1988). In teleosts, the simultaneous presence in an oocyte of ultrastructurally different cortical alveoli has been demonstrated (Ohta et al., 1990). In swordfish, on the basis of affinity to Pas reaction and abSal-Zrp immunoreactivity, at least two types of cortical alveoli seem to be present. abSal-Zrp immunopositive cortical alveoli could be supposed to be the site of accumulation and metabolism of exogenous proteins internalised by oocytes before they are resecreted on the inside of the growing oocyte eggshell ( $D r$. Oppen-Berntsen, personal communication).

Vtg uptake in swordfish starts in oocytes having a minimum diameter of $250 \mu \mathrm{m}$, as revealed by immunohistochemical staining with both abSwoVtg. The immunostaining, mainly localised in the ooplasm, increased in intensity during vitellogenesis and finally fell in post-vitellogenic oocytes.

It is apparent that the initial oocyte internalisation of hepatic Zrp in the swordfish starts before the uptake of $\mathrm{Vtg}$ and that it is associated with low previtellogenic estradiol plasma levels and $I_{G}$ values, while increase in plasma $E_{2}$ levels and $I_{G}$ values are associated with the beginning of Vtg uptake. In rainbow trout and Atlantic salmon Zrp hepatic synthesis seems to be induced by lower $E_{2}$ plasma levels than for Vtg (Hyllner et al., 1994; Celius \& Walter, 1998). This would appear to confirm the hypothesis that the differential and sequential induction of zonagenesis and vitellogenesis may reflect a general feature of teleost oogenesis.

In our study an increase in both $E_{2}$ plasma levels and $I_{G}$ values was correlated with the presence of post-vitellogenic oocytes. In most of the teleosts studied previously, $E_{2}$ is highest in late vitellogenesis and sharply declines in fish with post-vitellogenic ovaries (Matsuyama et al., 1991; Lee \& Yang, 2002). In vitro experiments have revealed that only vitellogenic follicles produce $\mathrm{E}_{2}$ (Kagawa et al., 1983a, 1984) and, as reported for other teleosts with asynchronous-type ovaries (Kagawa, 1983b; Kjesbu et al., 1996), the absence of a decline in plasma $E_{2}$ levels in post-vitellogenic swordfish can be correlated with the contemporaneous presence of vitellogenic oocytes.

\section{Acknowledgements}

We wish to thank prof. Antonio Lauria for his critical revision that helped to improve the manu- 
script considerably and prof. Anna Caroli and prof. Francesco Campobasso for their assistance with the statistical analyses. We wish also to thank Mr. Franco Scarciglia, owner and commander-in-chief of the fishing vessel "La Scogliera", who made the sample collection possible, and Mrs. Annunziata Marinelli, Mr. Vincenzo Pesola, Mr. Martino Cacucci and Mr. Angelo Disabato for their technical assistance. This work was partially supported by an EU project SIDS Contract Nr: QLRT-PL 199901567, and partially by "Fondi di Ateneo 2001" from the University of Bari.

\section{References}

Arocha F, Lee DW. The spawning of swordfish from the Northwest Atlantic. ICCAT Coll Vol Sc Pap 1995; 44:179-86.

Arocha F. Oocyte development and maturity classification of swordfish from the north-western Atlantic. J Fish Biol 2002; 60:13-27.

Celius T, Walter BC. Oogenesis in Atlantic salmon (Salmo salar L.) occurs by zonagenesis preceding vitellogenesis in vivo and in vitro. $\mathrm{J}$ Endocrinol 1998; 158:259-66.

Coello S, Grim AS. Development of Balbiani's vitelline body in the oocytes of the Atlantic mackerel, Scomber scombrus L.J Fish Biol $1990 ; 36: 265-267$.

Corriero A, Desantis S, Deflorio M, Acone F, Bridges CR., de la Serna JM., Megalofonou P, De Metrio G. Histological investigation on the ovarian cycle of the eastern Atlantic bluefin tuna (Thunnus thynnus L.). J Fish Biol 2003; 63:108-119.

Cuisset $B$, Pradelles $P$, Kime DE, Kühn ER, Babin P, Davail $S$, Le Menn F. Enzyme immonoassay for 11-ketotestosterone using acetylcholinesterase as label: application to the measurement of 11ketotestosterone in plasma of Siberian sturgeon. Comp Biochem Physiol 1994; 108C:229-41.

De La Serna JM, Ortiz de Urbina JM, Macias, D. Observations on sexratio, maturity and fecundity by length-class for swordfish (Xiphias gladius) captured with surface longline in the western Mediterranean. ICCAT Coll Vol Sc Pap 1996; 45:115-39.

Desantis S, Corriero A, Labate M, De Metrio G, Yannopoulou A. Histological and histochemical study of ovaries of two swordfish (Xiphias gladius L.) from the Gulf of Taranto. Biol Mar Medit 1998; 5:686-89.

Desantis S, Labate M, Corriero A, Labate GM, and De Metrio G. Immunohistochemical evidence of seasonal changes of gonadotropes in male ruin lizard (Podarcis sicula campestris De Betta). Eur J Histochem 2000; 44:385-95.

DeMartini EE, Uchiyama H, Williams HA. Sexual maturity, sex-ratio, and size composition of swordfish, Xiphias gladius, caught by the Hawaii-based pelagic longline fishery. Fish Bull 2000; 98:489-506.

Eicker J. Reproductionsbiologie pelagischer Fische. Diploma Thesis, University of Düsseldorf 2001;58.

Hunter JR, Macewicz B, Sibert, JR. The spawning frequency of skipjack tuna, Katsuwonus pelamis, from the South Pacific. Fish Bull 1986; 84:895-903.

Hyllner SJ, Silversand C, Haux C. Formation of the vitelline envelope precedes the active uptake of vitellogenin during oocyte development in the rainbow trout, Oncorhynchus mykiss. Mol Reprod Dev 1994; 39:166-75.

Kagawa H, Young G, Nagahama Y. Relationship between seasonal plasma estradiol-17, and testosterone levels in vitro production by ovarian follicles of amago salmon (Oncorhyncus rhodurus). Biol Reprod 1983a; 29:301-09.

Kagawa $H$, Young G, Nagahama Y. Changes in plasma steroid hormone levels during gonadal maturation in female goldfish Carassius auratus. Bull Jap Soc Sci Fish 1983b; 49:1783-7.
Kagawa $H$, Young $G$, Nagahama $Y$. In vitro estradiol-17, and testosterone production by ovarian follicles of the goldfish, Carassius auratus. Gen Comp Endocrinol 1984; 54:139-43.

Kjesbu OS, Kryvi H, Norberg B. Oocyte size and structure in relation to blood plasma steroid hormones in individually monitored, spawning Atlantic cod. J Fish Biol 1996; 49: 1197-1215.

Lee WK, Yang SW. Relationship between ovarian development and serum levels of gonadal steroid hormones, and induction of oocyte maturation and ovulation in the cultured female Korean spotted sea bass Lateolabrax maculatus (Jeom-nong-eo). Aquaculture 2002; 207:169-83.

Mandich A, Massari M, Bottero S, Marino G. Histological and histochemical study of female germ cell development in the dusky grouper Epinephelus marginatus (Lowe, 1834). Eur J Histochem 2002; 46: 87-100.

Matsuyama M, Adachi S., Nagahama Y., Matsuura S. Diurnal rhythm of oocyte development and plasma steroid hormone levels in the female red sea bream, Pagrus major, during the spawning season. Aquaculture 1988; 73:357-72.

Matsuyama M, Fukuda T, Ikeura S, Nagaham Y, Matsuura M. Annual reproductive cycle of the captive female Japanese sardine Sardinops melanostictus: relationship to ovarian development and serum levels of gonadal steroid hormones. Mar Biol 1991; 108:21-9.

Megalofonou P, Dean JM, Metrio G, Wilson C, Berkeley S. Age and growth of juvenile swordfish, Xiphias gladius Linnaeus, from the Mediterranean Sea.J Exp Mar Biol Ecol 1995; 188:79-88.

Nash JP, Davail-Cuisset B, Bhattacharyya S, Suter H, Le Menn F, Kime DE. An enzyme linked immunosorbant assay (ELISA) for testosterone, $17 \beta$-estradiol, and $17 \alpha, 20 \beta$-dihydroxy-4-pregnen-3-one using acetylcholinesterase as tracer: Application to measurement of Diel patterns in rainbow trout (Oncorhynchus mykiss). Fish Physiol Biochem 2000; 22:355-63.

Ohta T, Iwamatsu T, Tanaka M, Yoshimoto Y. Cortical alveolus breakdown in the eggs of the freshwater teleost Rhodeus ocellatus ocellatus. Anat Rec 1990; 227:486-96.

Oppen-Berntsen DO, Arukwe A, Yadetie F, Lorens JB, Male R. Salmon eggshell protein expression: a marker for environmental estrogens. Mar Biotechnol 1999; 1: 252-60.

Oppen-Berntsen DO, Gram-Jensen E, Walther BT. Zona radiata proteins are synthesized by rainbow trout (Oncohynchus mykiss) hepatocytes in response to oestradiol-17. J Endocrinol 1992a; 135: 293-302.

Oppen-Berntsen DO, Hyllner SJ, Haux C, Helvin JK, Walter BT. Eggshell zona radiata proteins from cod (Gadus morhua) extra ovarian origin and induction by estradiol-17ß. Int J Dev Biol 1992b; $36: 247-54$

Potoschi, A, Cavallaro, G, Sturiale, P, Lo Duca G. Eggs and larvae of swordfish, tuna and albacore caught in the Ionian Sea. Biol Mar Medit 1994; 1:119-24.

Selman K, Wallace RA, Barr V. Oogenesis in Fundulus heteroclitus. V. The relationship of yolk vescicles and cortical alveoli. J Exp Zool $1988 ; 246: 42-56$.

Susca V, Corriero A, Bridges CR, De Metrio G. Study of the sexual maturity of female bluefin tuna: purification and partial characterization of vitellogenin and its use in an enzyme-linked immunosorbent assay. J Fish Biol 2001; 58:815-31.

SAS. SAS/STAT@ User's guide. Release 6.03 Edition. Institute Inc, Cary, NC, USA 1988.

Taylor R G, Murphy M. Reproductive biology of the swordfish Xiphias gladius in the Straits of Florida and adjacent waters. Fish Bull 1992; 90:809-16.

Wallace R A. Vitellogenesis and oocyte growth in nonmammalian vertebrates. In: Browder RW, ed. Developmental Biology: A Comprehensive Synthesis. Plenum Press, New York 1985;127-77.

Walther B T. Nutritive strategies during pregastrula ontogenesis, and in evolution of enveloped zygotes: the embryogen hypothesis on sexual reproduction and hatching. In: Walther BT., Fyhn $\mathrm{HJ}$, eds. Physiological and Biochemical Aspects of Fish Development. University of Bergen, Norway 1993:2-21. 
A. Corriero et al. 